\title{
Examining the key performance indicators of all- star players and winning teams in elite futsal
}

João Santos, César Mendez-Domínguez, Célia Nunes, Miguel A. Gómez \& Bruno Travassos

To cite this article: João Santos, César Mendez-Domínguez, Célia Nunes, Miguel A. Gómez \& Bruno Travassos (2020) Examining the key performance indicators of all-star players and winning teams in elite futsal, International Journal of Performance Analysis in Sport, 20:1, 78-89, DOI: 10.1080/24748668.2019.1705643

To link to this article: https://doi.org/10.1080/24748668.2019.1705643

Published online: 25 Dec 2019.

Submit your article to this journal $₫$

Џll Article views: 147

Q View related articles 5

View Crossmark data $\longleftarrow$ 


\title{
Examining the key performance indicators of all-star players and winning teams in elite futsal
}

\author{
João Santos $\mathbb{D}^{\mathrm{a}, \mathrm{b}}$, César Mendez-Domínguez $\mathbb{D}^{c}$, Célia Nunes $\mathbb{D}^{\mathrm{d}}$, Miguel A. Gómez $\mathbb{D}^{c}$ \\ and Bruno Travassos $\left(\mathbb{D}^{\mathrm{a}, \mathrm{b}, \mathrm{e}}\right.$ \\ aResearch Center in Sports Sciences, Health Sciences and Human Development, CIDESD, Vila Real, Portugal; \\ ${ }^{b}$ Department of Sport Sciences, University of Beira Interior, Covilhã, Portugal; 'Physical Activity and Sport \\ Sciences, Technical University of Madrid, Madrid, Spain; ${ }^{d}$ Department of Mathematics and Center of \\ Mathematics and Applications, University of Beira Interior, Covilhã, Portugal; ePortugal Football School, \\ Portuguese FA, Lisbon, Portugal
}

\begin{abstract}
Purpose: to identify the key performance indicators that discriminate all-star from non-all-star players; and to differentiate winning from drawing/losing teams during the Euro Cup 2018 Futsal (Slovenia). Methods: the sample consisted of all matches $(n=20)$ played by 12 teams (87 players). Differences between both players and teams were calculated using the Mann-Whitney $\mathrm{U}$ and student-t tests and the binary logistic regression (assessing the relationship between all-star players or winning teams and several match- and contextually based variables). Results: minutes per match, goals, assists, ball recoveries, \% shots on target, \% key pass accuracy, and \% challenges won discriminated all-star from non-all-star players. However, only minutes per match (OR: 1.329), goals (OR: 13.547), and ball recoveries (OR: 2.136) per time played were determined to differentiate all-star players. Regarding the team analysis, the following variables discriminated winning from losing/drawing teams: goals, assists, \% counterattack success, and $\%$ set pieces success. However, only goals (OR: 2.035) and \% set piece success (OR: 1.076) predicted the match outcome. Conclusions: the current findings can help coaches to a better understanding of which key performance indicators are important out of all data available, contributing to defining priorities when training and managing competition in elite futsal.
\end{abstract}

\section{ARTICLE HISTORY}

Received 29 October 2019

Accepted 13 December 2019

\section{KEYWORDS}

Indoor soccer; top vs bottom players; success;

performance analysis

\section{Introduction}

Notational analysis research has been focused on identifying the key performance indicators (KPI) that best assist coaches and performance analysts during training and competitions. This approach allows modelling and characterising the players and teams' performance profiles in different contexts (Hughes \& Franks, 2015). Despite this relevant research area, the main team sports analysed under this approach were football, basketball or volleyball, with a scarce body of research focused on futsal. Specifically, performance analysis in futsal can be established based on the available research in team sport 
considering three set of variables: (i) those related to teams' effectiveness in different match contexts; (ii) those related to comparisons between the winning and losing teams and, as well, the best and worst teams across various leagues; and (iii) those related to the effect of contextual factors in team's and player's performance.

According to this approach, the research focused on team's effectiveness has identified a range of KPI that clearly characterises the team's performances in specific match contexts (e.g. ball possession). In particular, ball possession effectiveness in futsal is constrained by the opponent's strength, the number of passes, the end zone of ball possession, and the presence of the goalkeeper as an outfield player (Corrêa, Davids, Silva, Denardi, \& Tani, 2014; Gómez, Moral, \& Lago-Peñas, 2015; Méndez, Rodriguez, Ruano, Rúiz, \& Cui, 2017; Vicente-Vila \& Lago-Peñas, 2016). Ultimately, the use of the goalkeeper as an outfield player was revealed as the worst game strategy for achieving more goals when compared with counterattacks, positional attack, and set-pieces (Alves \& Bueno, 2012; Leite, 2012; Marchi, Silva, Scramin, Teixeira, \& Chiminazzo, 2010; Santos \& Navarro, 2010). However, Fukuda and Santana (2012) also reported any differences between positional attacks, counterattacks, set pieces and goalkeeper as an outfield player in the percentage of goals achieved in 14 matches of the Brazilian main league. In addition, more than $70 \%$ of the shots that ended in a goal were made in the central field and within the goal area itself (Abdel-Hakim, 2014; Alvarez, Hermoso, \& Vera, 2004; Gómez et al., 2015; Pessoa, Silva, Matias, \& Greco, 2009; Santos \& Navarro, 2010; Sarmento et al., 2016).

Secondly, regarding the KPI that best discriminate winning and losing teams or best and worst teams, several studies have identified contradictory results. On the one hand, some analyses of World Cup and UEFA Futsal Euro (Abdel-Hakim, 2014; Göral, 2018; Souza, Ribeiro, Rocha, Fernandes, \& Moreira, 2013) reported that winning teams were characterised by higher number of goals scored, total shots, shots on target, and more effectiveness than losing teams. However, other study examining 40 matches from the first Brazilian league identified that winning teams were differentiated from losing teams by a higher number of ball recoveries and a lower number of lost balls (Miloski, Pinho, Freitas, Marcelino, \& Arruda, 2014). These confronting results require a deeper analysis and further research is needed considering different leagues and competitions in their research designs.

Thirdly, the importance of contextual factors was investigated revealing the importance of match status, match location, quality of opposition or match period when analysing the ball possession effectiveness (Gómez et al., 2015), attack-defence transitions (Loureiro, 2013), attacking profiles (Méndez, Travassos, Santos, Ribeiro, \& Gonçalves, 2019) players dismissals (Gómez, Méndez, Indaburu, \& Travassos, 2019) and goalkeeper as an outfield player (Méndez, Gómez, Rúiz, \& Travassos, 2019; Méndez et al., 2017; Méndez-Domínguez, Gómez-Ruano, Rúiz-Pérez, \& Travassos, 2019). Despite the importance of those previous studies to understand the futsal game, there is a need to develop more research focused on the understanding of the match performance from different perspectives and considering different KPI. For instance, beyond analysing the behaviour of the teams, it would be interesting to undertake some studies with a focus on individual players' performance (Sampaio, Drinkwater, \& Leite, 2010; Sampaio et al., 2015). To our knowledge, no research has been conducted with the goal of understanding what characterises the teams (e.g. successful/unsuccessful or best/worst) and players' performances (all-star and non-all-star) . Interestingly, in other team sports such as basketball or football, it has been investigated the 
KPI that best define the performance profile based on the role of players (e.g. important/less important; Sampaio et al., 2010) or the level of players (e.g. all-stars/non-all-stars; Sampaio et al., 2015). According to this research approach, further research is required in order to capture in futsal those KPI that allow discriminating all-stars from non-all-star players. Based on the above rationale, the aim of this study was twofold: to identify the key performance indicators that discriminate all-star from non-all-star players; and to differentiate winning from drawing/losing teams during the Euro Cup 2018 Futsal (Slovenia). We expected to identify the offensive and defensive KPIs that best discriminate high-level teams and all-star players.

\section{Material and methods}

\subsection{Participants}

Archival data were obtained from the 20 matches played at Euro Cup 2018 of Futsal (Ljubiajna, Slovenia), which was retrieved from the InStat Scout ${ }^{\circledR}$ website. For the collective analysis, 12 teams and 20 matches (12 from the group phase and 8 from the playoffs) were examined. For the analysis of individual performances, 87 players were considered; these represented only the players who had advanced from group stage to the play-offs stage and were not goalkeepers.

\subsection{Data processing}

The variables derived from match-statistics were observed, selected, and transferred to a unified matrix on an excel spreadsheet. Instat Scout ${ }^{\oplus}$ is a common computer tool that provides data analysis of futsal competitions; it often provides the statistical analysis used by scouting services for the elite futsal leagues.

For the players' analysis, the following factors were considered: (i) individual characteristics (age and minutes played per match); (ii) actions taken during offensive plays (goals, assists, shots, lost balls, fouls shot, \% shots on target, \% pass accuracy, \% key pass accuracy, \% successful dribbles); (iii) actions taken during defensive plays (ball recoveries, fouls committed, \% challenges won, \% tackles won); and (iv) disciplinary calls (cards, yellow cards, and red cards). All the variables were divided by the amount of played time (minutes) in order to obtain a fair analysis (Sampaio et al., 2015).

For the team analysis, the following variables were considered: goals, assists, lost balls, shots, \% shots on target, dribbles, \% successful dribbles, \% possession ball, \% pass accuracy, $\%$ key pass accuracy, \% challenges won, ball recoveries, fouls committed, positional attacks, $\%$ positional attacks success, counterattacks, \% counterattacks success, set pieces, and \% success in set pieces.

\subsection{Statistical analysis}

A descriptive statistical analysis was used to describe the obtained results for each group. Firstly, data normality assumptions were calculated using the Shapiro-Wilk test to check the use of non-parametric or parametric analysis. Then, the Mann-Whitney U (nonparametric) and student-t (parametric) tests were considered to check univariate 
differences between players (all-star vs non-all-star) and teams (winning vs drawing/ losing), adding the effect size, $r$ Pearson (non-parametric) and $d$ Cohen (parametric), for each KPI. Their interpretation was based on the following criteria: Pearson $r, 0.1-0,3$ small, 0,3-0,5 medium, > 0,5 large effect size; Cohen $d, 0,2-0,5$ small, 0,5-0,8 medium, > 0,8 large effect size (Cohen, 1988). Secondly, two binomial logistic regression models were used to assess the multivariate relationship between the features of players (all-star vs non-all-star) and teams (winning vs drawing/losing) with the KPI and contextual-match related factors. In order to run both models, the stepwise selection method was considered. The results were reported using the odds ratio (OR) estimates and their 95\% confidence intervals (CI). To evaluate the quality of the adjustment, the Nagelkerke's $\mathrm{R}$ squared was used; its interpretation was based on the following criteria: 0.02-0.13 small, 0.13-0.26 medium, and $>0.26$ large effect size (Cohen, 1988). The performance of the model was assessed through the Hosmer-Lemeshow test and the area under the ROC curve (AUC) was used to evaluate the discriminative capacity of the model. The relationships between players and round variables were determined using Fisher's exact test (Crosstabs Command). Statistical analyses were conducted using the statistical software IBM SPSS for Windows version 22 (IBM. Corp. Armonk, NY) and the significance level was set to 0.05 .

\section{Results}

\subsection{All-star vs non-all-star players}

The means and standard deviations of the variables according to the all-star vs non-allstar categories are presented in Table 1 . The variables that significantly differentiated these two groups, per minute of play, were: minutes per match; goals; assists; ball recoveries; \% shots on target; \% key pass accuracy; and \% challenges won. In all statistically

Table 1. Means, standard deviations and p-values (mean differences) between all-star and non-all-star groups.

\begin{tabular}{llcccc}
\hline \multirow{5}{*}{ Group } & \multicolumn{1}{c}{ Variable } & $\begin{array}{c}\text { All-star players } \\
(\mathrm{n}=12)\end{array}$ & Non-all-star players $(\mathrm{n}=75)$ & $\mathrm{p}$-value & ES \\
\hline Individual & Age & $27.42 \pm 3.80$ & $28.29 \pm 3.64$ & $0.444^{\# 1}$ & $0.24^{\# 3}$ \\
& Minutes/match & $24.54 \pm 6.55$ & $14.26 \pm 7.15$ & $0.000^{\# 1^{* * *}}$ & $1.45^{\# 3}$ \\
Offensive & Goals & $0.03 \pm 0.02$ & $0.01 \pm 0.02$ & $0.000^{\# 2^{* * *}}$ & $0.41^{\# 4}$ \\
& Assists & $0.02 \pm 0.02$ & $0.01 \pm 0.01$ & $0.000^{\# 2^{* * *}}$ & $0.38^{\# 4}$ \\
& Shots & $0.25 \pm 0.08$ & $0.23 \pm 0.24$ & $0.111^{\# 2}$ & $0.17^{\# 4}$ \\
& Lost balls & $0.16 \pm 0.05$ & $0.20 \pm 0.12$ & $0.262^{\# 2}$ & $0.12^{\# 4}$ \\
& Fouls suffered & $0.05 \pm 0.03$ & $0.04 \pm 0.06$ & $0.124^{\# 2}$ & $0.17^{\# 4}$ \\
& \% Shots on target & $44.61 \pm 11.07$ & $33.91 \pm 20.37$ & $0.024^{\# 2^{* *}}$ & $0.24^{\# 4}$ \\
& \% Pass accuracy & $88.47 \pm 3.45$ & $86.25 \pm 7.02$ & $0.258^{\# 2}$ & $0.12^{\# 4}$ \\
& \% Key pass accuracy & $50.52 \pm 20.29$ & $27.31 \pm 26.29$ & $0.002^{\# 2^{* *}}$ & $0.32^{\# 4}$ \\
& \% Successfull dribles & $39.06 \pm 16.53$ & $37.67 \pm 27.96$ & $0.805^{\# 2}$ & $0,03^{\# 4}$ \\
Defensive & Ball recoveries & $0.18 \pm 0.05$ & $0.12 \pm 0.08$ & $0.013^{\# 1^{* *}}$ & $0.79^{\# 3}$ \\
& Fouls committed & $0.04 \pm 0.02$ & $0.06 \pm 0.09$ & $0.993^{\# 2}$ & $0.00^{\# 4}$ \\
& \% Challenges won & $53.65 \pm 7.37$ & $45.96 \pm 17.55$ & $0.013^{\# 1^{* *}}$ & $0.46^{\# 3}$ \\
& \% Tackles won & $72.26 \pm 14.30$ & $67.07 \pm 24.66$ & $0.481^{\# 1}$ & $0.22^{\# 3}$ \\
Discipline & Cards & $0.01 \pm 0.01$ & $0.01 \pm 0.02$ & $0.896^{\# 2}$ & $0.02^{\# 4}$ \\
& Yellow cards & $0.01 \pm 0.01$ & $0.01 \pm 0.02$ & $0.981^{\# 2}$ & $0.00^{\# 4}$ \\
& Red cards & $0.00 \pm 0.00$ & $0.00 \pm 0.00$ & $0.138^{\# 2}$ & $0.27^{\# 4}$ \\
\hline
\end{tabular}

Note: The variables expressed as counts were divided by minutes played.

Legend: \#1 t-test for independent samples; \#2 Mann-Whitney test; ${ }^{*} p<0.1 ;{ }^{* *} p<0.05 ;{ }^{* *} p<0.001$; \#3 d Cohen test; \#4 r Pearson test; 
Table 2. Frequencies ( $\mathrm{n}$ and \%) of all-star players and non-all-star players per round as the relation between both.

\begin{tabular}{lccrrc}
\hline Round & Achieve quarter-finals & Achieve semi-finals & Finalist & Winner & $\begin{array}{c}p \text {-value } \\
\text { (Fisher's exact test) }\end{array}$ \\
\hline Non-all-star (75) & $37(92 \%)$ & $21(87 \%)$ & $10(83 \%)$ & $7(64 \%)$ & 0.202 \\
All-star (12) & $3(8 \%)$ & $3(13 \%)$ & $2(17 \%)$ & $4(36 \%)$ & \\
\hline
\end{tabular}

significant variables, the all-star group presented a higher mean than the non-all-star group. The remaining variables did not show any significant difference. Interestingly, the round achieved was not associated with the classification between all-star and non-allstar players (see Table 2).

The binary logistic regression model allowed identifying the statistically significant variables of: Minutes per match, goals, and ball recoveries per 20 minutes played (see Table 3). The results revealed that all-star players played more minutes/match $(\mathrm{OR}=1.329$, with each minute increasing the possibility of individual players being considered all-star by 32.9\%); scored more goals $(\mathrm{OR}=13.547$, with each goal increasing 13 times more the possibility of individual player considered all-star); and made more ball recoveries $(\mathrm{OR}=2.136$, with each ball recovery contributing to increase 2 times more the possibility of each player being considered all-star). The model presents an $\mathrm{R}^{2}$ Nagelkerke $=0,566$, which means a large effect size. There also was good discriminant capacity, since AUC $=0.927$.

\subsection{Winning vs losing/draw teams}

The means and standard deviations of the KPI, based on a comparison between the winning teams vs those whose matches ended in a loss/draw are presented in Table 4 . The KPIs that significantly differentiated both groups were: goals, assists, \% counterattacks success, and \% set pieces success. In all significant variables the winning teams presented a higher mean that the losing teams.

The binary logistic regression model identified the following significant KPI: goals and $\%$ set pieces success (see Table 5 ). The results revealed that winning teams scored more goals per match $(\mathrm{OR}=2.035$, with each goal increasing 2 times more the possibility of a team winning a match) and had a better success rate at set pieces $(\mathrm{OR}=1.076$, with each successful set piece increasing the possibility of a team winning a match by $7.6 \%$ ). The model presents an $\mathrm{R}^{2}$ Nagelkerke $=0.414$, which indicates a large effect size. It can be assumed that there was a good discriminant capacity, since AUC $=0.832$.

Table 3. Binary logistic regression model (all-star vs non-all-star players).

\begin{tabular}{|c|c|c|c|c|c|}
\hline & \multirow[b]{2}{*}{ B } & \multirow{2}{*}{$\frac{p \text {-value }}{\text { (Wald) }}$} & \multirow[b]{2}{*}{ OR } & \multicolumn{2}{|c|}{ IC 95\% OR } \\
\hline & & & & Lower & Upper \\
\hline Minutes/match & 0.284 & 0.001 & 1.329 & 1.117 & 1.581 \\
\hline Goals_20min & 2.606 & 0.014 & 13.547 & 1.696 & 108.182 \\
\hline Ball recoveries_20min & 0.759 & 0.041 & 2.136 & 1.031 & 4.429 \\
\hline Constant & -10.789 & 0.000 & 0.000 & & \\
\hline
\end{tabular}

$\mathrm{R}^{2}$ Nagelkerke $=0.566 ; p$ Hosmer and Lemeshow $=0.938 ; \%$ Global Correct $=92 \% ; \mathrm{AUC}=0.927$ 
Table 4. Means, standard deviations and p-values (mean differences) from winning and lost/draw groups.

\begin{tabular}{llcccc}
\hline \multirow{2}{*}{ Group } & \multicolumn{1}{c}{ Variable } & $\begin{array}{c}\text { Winning } \\
(\mathrm{n}=15)\end{array}$ & $\begin{array}{c}\text { Lost/draw } \\
(\mathrm{n}=25)\end{array}$ & $\mathrm{p}$-value & ES \\
\hline Offensive & Goals & $3.33 \pm 2.06$ & $1.64 \pm 1.29$ & $0.004^{\# 2^{* *}}$ & $0.44^{\# 4}$ \\
& Assists & $1.80 \pm 1.15$ & $1.20 \pm 1.19$ & $0.081^{\# 2^{*}}$ & $0.28^{\# 4}$ \\
& Lost balls & $29.47 \pm 7.52$ & $28.32 \pm 6.93$ & $0.626^{\# 1}$ & $0.16^{\# 3}$ \\
& Shots & $37.69 \pm 7.14$ & $35.20 \pm 11.01$ & $0.396^{\# 1}$ & $0.25^{\# 3}$ \\
& \% Shots on target & $37.16 \pm 9.59$ & $35.51 \pm 9.74$ & $0.603^{\# 1}$ & $0.17^{\# 3}$ \\
& Dribbles & $25.20 \pm 9.81$ & $22.48 \pm 8.10$ & $0.348^{\# 1}$ & $0.31^{\# 3}$ \\
& \% Successful dribbles & $46.14 \pm 12.62$ & $42.97 \pm 10.67$ & $0.401^{\# 1}$ & $0.28^{\# 3}$ \\
& \% Possession ball & $50.20 \pm 8.32$ & $49.88 \pm 11.39$ & $0.925^{\# 1}$ & $0.03^{\# 3}$ \\
& \% Pass accuracy & $87.86 \pm 3.16$ & $87.61 \pm 4.13$ & $0.978^{\# 2}$ & $0.01^{\# 4}$ \\
& \% Key pass accuracy & $57.48 \pm 16.36$ & $53.86 \pm 17.36$ & $0.594^{\# 2}$ & $0.09^{\# 4}$ \\
\% Challenges won & $51.94 \pm 7.00$ & $48.84 \pm 7.17$ & $0.322^{\# 2}$ & $0,16^{\# 4}$ \\
Tactical & Ball recoveries & $30.07 \pm 6.80$ & $27.60 \pm 6.75$ & $0.272^{\# 1}$ & $0.36^{\# 3}$ \\
& Fouls committed & $6.87 \pm 2.53$ & $6.24 \pm 2.24$ & $0.420^{\# 1}$ & $0.27^{\# 3}$ \\
& Positional attacks & $73.27 \pm 15.16$ & $78.56 \pm 12.83$ & $0.245^{\# 1}$ & $0.39^{\# 3}$ \\
& \% Positional attacks success & $25.47 \pm 4.79$ & $23.56 \pm 5.97$ & $0.301^{\# 1}$ & $0.34^{\# 3}$ \\
& Counterattacks & $7.47 \pm 3.29$ & $6.32 \pm 3.28$ & $0.291^{\# 1}$ & $0.35^{\# 3}$ \\
& \% Counterattacks success & $58.13 \pm 17.83$ & $44.32 \pm 24.98$ & $0.069^{\# 1^{*}}$ & $0.61^{\# 3}$ \\
& Set Pieces & $24.33 \pm 20.08$ & $21.00 \pm 11.72$ & $0.604^{\# 2}$ & $0.08^{\# 4}$ \\
& \% Set pieces success & $75.80 \pm 7.67$ & $65.28 \pm 15.42$ & $0.007^{\# 1^{* *}}$ & $0.80^{\# 3}$ \\
\hline
\end{tabular}

Legend: \#1 t-test for independent samples; \#2 Mann-Whitney test; ${ }^{*} p<0.1 ;{ }^{* *} p<0.05 ;{ }^{* * *} p<0.001$; \#3 d Cohen test; \#4 r Pearson test;

Table 5. Binary logistic regression model (winning vs losing/draw).

\begin{tabular}{|c|c|c|c|c|c|}
\hline & \multirow[b]{2}{*}{ B } & \multirow{2}{*}{$\frac{p \text {-value }}{\text { (Wald) }}$} & \multirow[b]{2}{*}{ OR } & \multicolumn{2}{|c|}{ IC 95\% OR } \\
\hline & & & & Lower & Upper \\
\hline Goals & 0.710 & 0.013 & 2.035 & 1.161 & 3.567 \\
\hline$\%$ Set pieces success & 0.073 & 0.038 & 1.076 & 1.004 & 1.153 \\
\hline Constant & -10.789 & 0.009 & 0.001 & & \\
\hline
\end{tabular}

$\mathrm{R}^{2}$ Nagelkerke $=0.414 ; \%$ Global Correct $=75 \% ; \mathrm{AUC}=0.832$

\section{Discussion and conclusion}

This study aimed to identify performance indicators that discriminate all-star from nonall-star players and winning from drawing/losing teams in the Euro Cup 2018 Futsal. The results indicated the high level of all-star players and winning teams in some of the offensive and defensive KPI studied (goals, assists, ball recoveries, \% shots on target, \% key pass accuracy, \% challenges won, \% counterattacks success and \% set pieces success). These findings are in line with previous studies (Abdel-Hakim, 2014; Göral, 2018; Lago-Peñas, Lago-Ballesteros, \& Rey, 2011; Miloski et al., 2014), but with singular aspects that should be addressed.

\subsection{All-star vs non-all-star players}

The results indicated differences between the all-star and non-all-star groups. More specifically, the variables that discriminate the two groups were: minutes per match; goals; assists; ball recoveries; \% shots on target; \% key pass accuracy; and \% challenges won. Firstly, the all-star players played more minutes per match than the non-all-star players. This finding is consistent with that of Sampaio et al. (2010) in relation to 
basketball players where the group with more minutes played had better stats (and were considered by coaches to be the best players). This result is something to be expected since the coaches put the best players on the court for the most time possible. Nonsignificant differences were found between groups in terms of their age. It means that independently of their age, the players' capabilities to really adjust their behaviour to the performance context and achieve efficacy were the most key variables to determine all-stars from non-all-star players. To our best knowledge, any other study revealed evidences about the effect of age in all-stars and non-all-star players. Further research is required in different team sports regarding the effects of players' age in their performance and on the achievement of all-stars distinction.

Regarding offensive KPI, the all-star players achieved a higher number of goals and assists; a better rate of shots on target; and greater key pass accuracy. Similar to basketball, Sampaio et al. (2015) found that all-star players had a better performance than the other players related to offence variables during an NBA season. In particular, all-star players in futsal are selected by a scouting team; further, it is expected that the best players will contribute most to achieving the sport's main objective (scoring a goal). The all-star group had more goals per minutes played, but any differences were observed between groups in terms of the number of shots made. A similar event seems to happen when we analyse the related pass variables, since the rate of pass accuracy did not differ between groups. However, the all-star group had a better rate of key passes accuracy, i.e. the passes which contributed directly to a finalisation situation and could facilitate the chance to score a goal in the best group. That is, such results come to reinforce previous results that stressed that all star players distinguish their performance from the other players not achieving more actions per se but achieving higher levels of individual and collective effectiveness (Abdel-Hakim, 2014; Göral, 2018; Souza et al., 2013).

No differences were found between groups in fouls suffered, lost balls, or rate of dribble success. Concerning defensive variables, the all-star group showed a higher mean of ball recoveries and a higher rate of challenges won but showed no difference in fouls committed or rate of tackles won. It seems that 1on 1 are important when trying to discriminate best players, a finding consistent with Amaral and Garganta (2005) who found that this configuration appears to encourage the defensive imbalance of the opponent. It thus serves as a stimulating factor for shooting chances (by increasing the likelihood of an imbalance in the defensive structure adversary by dribbling). However, more studies on this topic are needed. No differences were found in discipline-related factors. Although there were seven variables with significant differences between groups, only three KPIs (minutes per match, goals, and ball recoveries per 20 minutes of playing time) were statistically significant in the binary logistic regression model. Thus, only these three KPIs predicted the selection of all-star players. The number of goals per 20 minutes $(\mathrm{OR}=13.547)$ predicted whether a player would be an all-star (that is, each goal made by the player per 20 minutes of match time increased 13 times more the probability of being appointed all-star). As mentioned earlier, scoring more goals than the opponent is the main objective of futsal. It thus makes sense that players who score more goals would be the all-star players of the tournament. Interestingly, the variable assists per time was not statistically significant. This finding was somewhat surprising, as assists are a very important aspect of the game. The second most relevant KPI was ball recoveries per 20 minutes of match time $(\mathrm{OR}=2.136)$ : for each additional 
ball recovery per 20 minutes, the probability of prediction as an all-star player is increased twofold. First, a ball recovery can originate defence-offence transitions with numerical superiority. This type of action, i.e. when the ball is lost to the other side, can be very risky (Leite, 2012; Santos \& Navarro, 2010; Sarmento et al., 2016) with the biggest percentage of goals scored made directly after such actions. Second, a ball recovery requires considerable skill, since one must be able to predict the next opponent's action and, as well, have a good understanding of the timing involved in a pass/ reception action (Corrêa, Vilar, Davids, \& Renshaw, 2014; Travassos, Araújo, Davids, Esteves, \& Fernandes, 2012). It has already been demonstrated (e.g. Farrow \& Abernethy, 2003) that better players have greater skill executing such actions than lesser skilful players.

The third KPI in the model was the minutes per match $(\mathrm{OR}=1.329)$ : for each minute that a player is in a match, the probability of that player being an all-star player increases $32.9 \%$. These results, as we noted earlier, were expected given that coaches try to put their best players in the match for the most time possible. Thus, if a player performs well during the early matches, it is fairly well expected that he will play even more time in the subsequent matches (Ibáñez, García, Feu, Lorenzo, \& Sampaio, 2009). Such results are in line with previous research in basketball that revealed that the competitive playing deficit affects the general performance of players in each match and throughout the season (Ibáñez et al., 2009; Lorenzo, Lorenzo, Conte, \& Giménez, 2019).

The results showed us also that the round achieved by players did not predict whether a player would be named an all-star player. There seems to be a trend in which the percentage of players selected as all-star players on each round increases as the player pool gets smaller. It is important to point out that we only considered those players who achieved the quarter-finals since, as mentioned earlier, all the all-star players achieved at least that round.

\subsection{Winning vs losing/draw teams}

The results indicated differences between winning and drawing/losing teams in four KPI: goals, assists, \% counterattack success, and \% set pieces success. With regards to offensive variables, the winning teams scored more goals and made more assists per match than the drawing/losing teams, thus supporting previous research made in this type of competition (i.e. elite-level tournaments; Abdel-Hakim, 2014; Souza et al., 2013). In terms of shooting, the results showed no differences in total shots made and in the rate shots on target. This is at variance with previous studies analysing similar competitions (AbdelHakim, 2014; Göral, 2018; Souza et al., 2013), in which these two variables distinguished winning from losing teams (i.e. reporting better performance on winning teams). However, Miloski et al. (2014), comparing winning and losing matches, did not find any difference in total shots or shots on target made. This study, however, analysed 40 matches of a single team during one season; it is thus not certain whether these results are generalisable. No differences were found in passing, dribbling, or possession ball percentage. Two other variables without significant differences were ball recoveries and lost balls. At the same time, these two variables were the only ones that discriminated winning from losing matches at Miloski et al. (2014). Our own results showed no differences in faults or card-related variables; in contrast, Göral (2018) found that winning teams had 
fewer yellow cards and fouls than losing teams (based only on frequencies, as opposed to statistical analyses).

In the current study, both rates of set pieces success and counterattacks success (i.e. ending situation) were able to discriminate winning from losing/drawing teams (with the winning group showing a better performance in both indicators). Regarding total frequencies of counterattacks and set pieces per match, there were non-significant differences between groups. These results seem to increase the importance of the success rates across these type of actions - a finding in agreement with previous studies (Leite, 2012; Santos \& Navarro, 2010; Sarmento et al., 2016), where most goals occurred in fast counterattacks and set pieces. More recently, Méndez-Domínguez et al. (2019) found that the top teams of European futsal leagues it was better attacking with counterattacks or set pieces and not do it with the 5 vs 4+ Goalkeeper strategy, which was that better discriminated against losing teams. The binary logistic regression model identified two significant KPI: goals and \% set piece success. On the one hand, goals per match $(\mathrm{OR}=2.035)$ was the variable that best predicted that a team would win a match (since, for each goal, a team's chance of winning increased twofold beyond the original amount). These results indicate that winning teams score more goals than losing teams (which is to be expected, since winning or losing depends on the number of goals per team). On the other hand, the rate of set piece success $(\mathrm{OR}=1.076)$ also predicted match outcome (since each percent increase in the rate of set pieces success raised the chance of winning by $7.6 \%$ ). This shows the tactical importance of set piece actions (i.e. corners and offensive throw-ins): they represent the fulfilment of planned, coordinated actions and, further, the situations in one of which the greatest number of goals happen (Leite, 2012). Our results reinforce the importance of the set pieces, since the teams more successful in the set pieces that ended in shots tended to win the match.

In conclusion, only goals and ball recoveries per time played and minutes per match were the KPIs that best predicted all-star player selection, while goals were the KPI with the highest impact. Concerning to predicting winning teams, only goals per match and the success rate of set pieces were found as significant. These results can help coaches to better discern important information from all match-data. In addition, coaches can define training priorities when preparing international competitions. The results can also help players to identify why some players were better than others were. As was mentioned before, it seems that the 1vs. 1 confrontations are a very impactful situation; however, more research is needed to understand the specific nature of this complex influence. Lastly, ball recoveries were important as KPI; then, additional research is needed to understand the manner and circumstance in which they directly affect the match outcome. The same issue raises when considering the rate of set pieces success (which, though traditionally considered an important stat, requires further investigation to determine which type of such plays, and under what conditions, their success rate could be increased). Overall, future works are needed to confirm the current findings in different futsal leagues of different levels of expertise. Also, based on KPI identified for all-star players it will be possible to calculate the most valuable player of each match or tournament. Also, it will be possible over each match to calculate a winning probability for each team based on the KPI identified for teams' performance. 


\subsection{Study limitations}

It is necessary to increase the sample size to have greater confidence in the differences of groups and achieve greater relevance in the analysed factors, ... in addition, categorical variables (match status, match type, and opposing level) could be included to provide of greater consistency to the multivariate model. Also, the competition type includes group stage matches but also others based on the knockout that may have influenced the teams and players behaviour.

\section{Disclosure statement}

No potential conflict of interest was reported by the authors.

\section{ORCID}

João Santos (D) http://orcid.org/0000-0002-1937-3398

César Mendez-Domínguez (D) http://orcid.org/0000-0003-1662-2448

Célia Nunes (D) http://orcid.org/0000-0003-0167-4851

Miguel A. Gómez (D) http://orcid.org/0000-0002-9585-3158

Bruno Travassos (D) http://orcid.org/0000-0002-2165-2687

\section{References}

Abdel-Hakim, H. (2014). Quantitative analysis of performance indicators of goals scored in the futsal world cup Thailand 2012. Pamukkale Spor Bilimleri Dergisi, 5(1), 113-127.

Alvarez, J., Hermoso, V., \& Vera, J. (2004). Effort profiling during indoor soccer competition. Journal of Sports Sciences, 22(1), 500-501.

Alves, I. P., \& Bueno, L. (2012). Analise dos gols na primeira fase da liga futsal 2012 [Analysis of goals in 2012 futsal league's games]. Revista Brasileira De Futsal E Futebol, 4(12), 118-124.

Amaral, R., \& Garganta, J. (2005). A modelação do jogo em futsal: Análise sequencial do $1 \times 1$ no processo ofensivo [Futsal game modeling: $1 \times 1$ sequential analysis in the offensive process]. Revista Portuguesa De Ciências Do Desporto, 5(3), 298-310.

Cohen, J. (1988). Statistical power analysis for the behavior sciences (2nd ed.). Hillsdale, NJ: Erlbaum.

Corrêa, U. C., Davids, K., Silva, S., Denardi, R. A., \& Tani, G. (2014). The influence of a goalkeeper as an outfield player on defensive subsystems in futsal. Advances in Physical Education, 4(2), 84-92.

Corrêa, U. C., Vilar, L., Davids, K., \& Renshaw, I. (2014). Informational constraints on the emergence of passing direction in the team sport of futsal. European Journal of Sport Science, $14(2), 169-176$.

Farrow, D., \& Abernethy, B. (2003). Do expertise and the degree of perception-action coupling affect natural anticipatory performance? Perception, 32(9), 1127-1139.

Fukuda, J. P. S., \& Santana, W. C. (2012). Analises dos gols em jogos da liga futsal 2011 [Analysis of goals in 2011 futsal league's games]. Revista Brasileira De Futsal E Futebol, 4(11), 62-67.

Gómez, M.-Á., Moral, J., \& Lago-Peñas, C. (2015). Multivariate analysis of ball possessions effectiveness in elite futsal. Journal of Sports Sciences, 33(20), 2173-2181.

Göral, K. (2018). Analysis of Serbia UEFA futsal Euro 2016 competitions in terms of some variables. Journal of Education and Training Studies, 6(10), 1-6.

Hughes, M., \& Franks, I. (2015). Essentials of performance analysis in sport. London: Routledge. 
Ibáñez, S. J., García, J., Feu, S., Lorenzo, A., \& Sampaio, J. (2009). Effects of consecutive basketball games on the game-related statistics that discriminate winner and losing teams. Journal of Sports Science \& Medicine, 8(3), 458-462.

Lago-Peñas, C., Lago-Ballesteros, J., \& Rey, R. (2011). Differences in performance indicators between winning and losing teams in the UEFA champions league. Journal of Human Kinetics, 27(1), 135.

Leite, W. S. (2012). Analysis of the offensive process of the Portuguese futsal team: A comparison between the actions of finalization. Pamukkale Spor Bilimleri Dergisi, 3(3), 78-89.

Lorenzo, J., Lorenzo, A., Conte, D., \& Giménez, M. (2019). Long-term analysis of elite basketball players' game-related statistics throughout their careers. Frontiers in Psychology, 10, 421.

Loureiro, M. A. B. (2013). A influência das variáveis contextuais na organização da transição ataque-defesa em futsal de alto rendimento. Estudo de caso realizado com uma equipa da $1^{a}$ Divisão Nacional de Futsal na época de 2011/2012 [The influence of contextual variables on the organization of the attack-defense transition in elite futsal. Case study conducted with a team from the 1st national futsal division during the 2011/ 2012 season] (Unpublished masters' thesis). Retrieved from repository.utl.pt

Marchi, R., Silva, C., Scramin, L., Teixeira, A., \& Chiminazzo, J. (2010). Incidência de gols resultantes de contra-ataques de equipes de futsal [Incidence of goals from futsal counterattacks]. Conexõe, 8(3), 16-22.

Méndez, C., Gómez, M., Rúiz, L. M., \& Travassos, B. (2019). Goalkeeper as an outfield player: Shooting chances at critical moments in elite futsal. International Journal of Performance Analysis in Sport, 19(2), 179-191.

Méndez, C., Travassos, B., Santos, J., Ribeiro, J. N., \& Gonçalves, B. (2019). Attacking profiles of the best ranked teams from elite futsal leagues. Frontiers in Psychology, 10, 1370.

Méndez, C. D., Rodriguez, J. M., Ruano, M. G., Rúiz, L. M., \& Cui, Y. (2017). The relevance of game and context variables in futsal goals scored in attack with goalkeeper as an outfield player. Paper presented at the Complex Systems in Sport International Congress, Linking Theory and Practice, Barcelona.

Méndez-Domínguez, C., Gómez-Ruano, M. A., Rúiz-Pérez, L. M., \& Travassos, B. (2019). Goals scored and received in 5vs4 GK game strategy are constrained by critical moment and situational variables in elite futsal. Journal of Sports Sciences, 37(1-9), 2443-2451.

Miloski, B., Pinho, J. P., Freitas, C. G., Marcelino, P. R., \& Arruda, A. F. S. (2014). Quais ações técnico-táticas realizadas durante as partidas de futsal podem discriminar o resultado de vitória ou derrota? [What technical-tactical actions taken during futsal matches can discriminate the outcome of victory or defeat?]. Revista Brasileira De Educação Física E Esporte, 28(2), 203-209.

Pessoa, V., Silva, V., Matias, C., \& Greco, P. (2009). Análise dos gols da liga futsal 2008 [Analysis of the goals of the futsal league 2008]. Lecturas, Educación Física Y Desportes, Buenos Aires, 13 (129), 1-5.

Sampaio, J., Drinkwater, E. J., \& Leite, N. M. (2010). Effects of season period, team quality, and playing time on basketball players' game-related statistics. European Journal of Sport Science, 10 (2), 141-149.

Sampaio, J., McGarry, T., Calleja-González, J., Sáiz, S. J., Alcázar, X. S., Balciunas, M., \& Perales, J. C. (2015). Exploring game performance in the national basketball association using player tracking data. PloS One, 10(7), e0132894.

Santos, M. A. B., \& Navarro, A. C. (2010). Analise dos gols da copa do mundo de futsal FIFA 2008 [Analysis of the goals of FIFA world cup of futsal in 2008]. Revista Brasileira De Futsal E Futebol, 2(4), 33-37.

Sarmento, H., Bradley, P., Anguera, M. T., Polido, T., Resende, R., \& Campaniço, J. (2016). Quantifying the offensive sequences that result in goals in elite futsal matches. Journal of Sports Sciences, 34(7), 621-629.

Souza, P., Ribeiro, R., Rocha, R., Fernandes, B., \& Moreira, E. (2013). Análise das finalizações como indicadores de rendimento em jogos de futsal [Shooting analysis as 
performance indicators in futsal games]. Revista Mackenzie De Educação Física E Esporte, 12(2), 89-99.

Travassos, B., Araújo, D., Davids, K., Esteves, P. T., \& Fernandes, O. (2012). Improving passing actions in team sports by developing interpersonal interactions between players. International Journal of Sports Science \& Coaching, 7(4), 677-688.

Vicente-Vila, P., \& Lago-Peñas, C. (2016). The goalkeeper influence on ball possession effectiveness in futsal. Journal of Human Kinetics, 51(1), 217-224. 